\title{
An Empirical Investigation of the Monetary Model Economic Fundamentals
}

\author{
Jean René Cupidon'1, Judex Hyppolite² \\ ${ }^{1}$ Department of Economics and Mathematics, Berea College, Berea, KY, USA \\ ${ }^{2}$ Department of Economics, Finance, and Real Estate, Monmouth University, West Long Branch, NJ, USA \\ Email: cupidonj@berea.edu, jhyppoli@monmouth.edu
}

How to cite this paper: Cupidon, J.R. and Hyppolite, J. (2016) An Empirical Investigation of the Monetary Model Economic Fundamentals. Modern Economy, 7, 1728-1740. http://dx.doi.org/10.4236/me.2016.714151

Received: November 10, 2016

Accepted: December 18, 2016

Published: December 21, 2016

Copyright $\odot 2016$ by authors and Scientific Research Publishing Inc. This work is licensed under the Creative Commons Attribution International License (CC BY 4.0).

http://creativecommons.org/licenses/by/4.0/ (c) (i) Open Access

\begin{abstract}
This paper presents an empirical investigation of an important series called "economic fundamentals" derived from the flexible price monetary model of exchange rate determination. The model predicts that the nominal exchange rate is determined by the "economic fundamentals", referred here as the series $f_{t}$. As a result, the characteristics of the "economic fundamentals" process may influence the properties of the nominal exchange rate process. We will just use the term "fundamentals". Nevertheless, many exchange rate models found in the literature assume an ad-hoc process for $f_{t}$ ignoring the fact that the specification of this process can be formally derived within the framework of the monetary model. Using data for several countries on GDP and money supplies, we construct the series $f_{t}$ according to the monetary model specification, and we examine some important characteristics of its empirical distribution such as skewness, kurtosis, stationarity, ARCH and GARCH properties. We observe that the series is not exactly normally distributed, as commonly assumed in many target zone models. This investigation essentially helps with modeling exchange rate and more importantly in the analysis of exchange rate target zones modeling by identifying potential restrictions that need to be taken into consideration when choosing a process for the modeling of the "economic fundamentals".
\end{abstract}

\section{Keywords}

Exchange Rates, Time Series

\section{Introduction}

The monetary model was originally developed as a framework to analyze Balance-ofpayments adjustments under a fixed exchange rate regime and has been modified after 
the Breakdown of the Bretton Woods system as a model of nominal exchange rate determination. The model is a common theme in textbooks on open-economy macroeconomics and in the literature. In addition, the model forms the basis of most target zone models and balance-of-payments studies. However, several versions of the monetary model have been developed over the years. In fact, Dornbusch [1] developed a sticky-price version of the model while Frenkel [2] and Mussa [3] developed a flexible price version. Dornbusch's sticky-price monetary model allows for short-run overshooting of the nominal exchange rate above its long-run value that is associated with purchasing power parity (PPP). But, according to Frankel (1979), the Sticky-price monetary model contains a deficiency in that it does not explicitly incorporate shortrun difference in secular rates of inflation between the two countries. To overcome this shortcoming, he introduced the real interest differential monetary model that combines elements of both the flexible-price and sticky-price monetary models.

\subsection{Derivation of the Exchange Rate Process}

The symbol $\star$ is used to denote foreign variables. A building block of the monetary model is purchasing power parity (PPP). The model makes four basic assumptions:

1) Money market equilibrium;

2) Continuous stock equilibrium in the money market;

3) Uncovered interest parity (UIP); and

4) Purchasing power parity.

Monetary equilibrium conditions in the domestic and foreign markets are given respectively by

$$
\begin{gathered}
m_{t}-p_{t}=\phi y_{t}-\alpha i_{t} \\
m_{t}^{\star}-p_{t}^{\star}=\phi^{\star} y_{t}^{\star}-\alpha^{v} i_{t}^{\star}
\end{gathered}
$$

The parameter $\phi$ is known as the income elasticity of money demand where $0<\phi<1$ and $\alpha$ is the interest rate semi-elasticity of money demand.

International capital market equilibrium is given by assuming that uncovered interest parity holds, that is,

$$
i_{t}-i_{t}^{\star}=\mathbb{E}_{t} s_{t+1}-s_{t},
$$

where $\mathbb{E}_{t}($.$) denotes expectation operator conditional on all publicly available infor-$ mation to economic agents at time $t$. Also, PPP states that $s_{t}=p_{t}-p_{t}^{\star}$. PPP is assumed to hold continuously in the model. Empirical studies show that PPP is violated in the short run but may hold in the long run. Now, we obtain

$$
m_{t}-m_{t}^{\star}-\left(p_{t}-p_{t}^{\star}\right)=\left(\phi y_{t}-\phi^{\star} y_{t}^{\star}\right)-\left(\alpha i_{t}-\alpha^{\star} i_{t}^{\star}\right)
$$

Using the PPP condition, we obtain the fundamental equation of the flexible price monetary model

$$
s_{t}=m_{t}-m_{t}^{\star}-\left(\phi y_{t}-\phi^{\star} y_{t}^{\star}\right)+\left(\alpha i_{t}-\alpha^{\star} i_{t}^{\star}\right)
$$

Under flexible exchange rates, the money stock is exogenous. 
As commonly done in the literature, we simplify the model by assuming that the income elasticities and interest rate semi-elasticities of money demand are the same for the domestic and foreign countries. In this case, the fundamental equation becomes

$$
s_{t}=m_{t}-m_{t}^{\star}-\phi\left(y_{t}-y_{t}^{\star}\right)+\alpha\left(i_{t}-i_{t}^{\star}\right)
$$

At this point, we can use the UIP condition to obtain

$$
s_{t}=m_{t}-m_{t}^{\star}-\phi\left(y_{t}-y_{t}^{\star}\right)+\alpha \mathbb{E}_{t}\left(\Delta s_{t+1}\right),
$$

Following Nelson Mark, we let

$$
f_{t}=m_{t}-m_{t}^{\star}-\phi\left(y_{t}-y_{t}^{\star}\right)
$$

We therefore obtain

$$
s_{t}=f_{t}+\alpha \mathbb{E}_{t}\left(\Delta s_{t+1}\right),
$$

This last version constitutes the fundamental equation of the flexible price monetary model in discrete time. This equation is basically a first order stochastic difference equation in the variable $s_{t}$ in expectation form.

The expression for $f_{t}$ is referred to as the "economic fundamentals" or the fundamental determinants of exchange rate determination.

To solve for $s_{t}$, it is more useful to rewrite the equation as follows

$$
s_{t}=\gamma f_{t}+\psi \mathbb{E}_{t} s_{t+1}
$$

where $\gamma=\frac{1}{1+\alpha}$ and $\psi=\frac{\alpha}{1+\alpha}$. This class of stochastic difference equations is usually solved by the method of undetermined coefficients or by repeated substitutions. This equation states that expectations of future values of the exchange rate, that is, $\mathbb{E}_{t} S_{t+1}$, are embodied in the current exchange rate. It also indicates that high relative money growth in the domestic country leads to a weakening of the home currency, while an increase in the relative domestic income leads to a strenghtening of the home currency. We can write

$$
s_{t+1}=\gamma f_{t+1}+\psi \mathbb{E}_{t+1} s_{t+2}
$$

It follows that

$$
\begin{aligned}
\mathbb{E}_{t} S_{t+1} & =\gamma \mathbb{E}_{t} f_{t+1}+\psi \mathbb{E}_{t+1} S_{t+2} \\
& =\gamma \mathbb{E}_{t} f_{t+1}+\psi \mathbb{E}_{t} S_{t+2}
\end{aligned}
$$

It follows that

$$
\begin{aligned}
s_{t} & =\gamma f_{t}+\mathbb{E}_{t} f_{t+1}+\psi^{2} \mathbb{E}_{t} s_{t+1}+\psi \gamma \mathbb{E}_{t} f_{t+1} \\
& =\gamma \mathbb{E}_{t} f_{t}+\gamma \psi \mathbb{E}_{t} f_{t+1}+\psi^{2} \mathbb{E}_{t} s_{t+2}
\end{aligned}
$$

In a similar fashion we obtain

$$
s_{t}=\gamma \mathbb{E}_{t} f_{t}+\gamma \psi \mathbb{E}_{t} f_{t+1}+\gamma \psi^{2} \mathbb{E}_{t} s_{t+3}
$$

Continuing the process, we obtain the following recursive equation

$$
S_{t}=\gamma \sum_{j=0}^{k} \psi^{j} \mathbb{E}_{t} f_{t+j}+\psi^{k+1} \mathbb{E}_{t} S_{t+k+1}
$$


If the following transversality condition

$$
\lim _{k \rightarrow+\infty} \psi^{k} \mathbb{E}_{t} S_{t+k}=0 \text {, }
$$

is imposed, we obtain the so-called "no-bubbles" or "rational expectations" solution by letting k go to infinity:

$$
S_{t}=\gamma \sum_{j=0}^{\infty} \psi^{j} \mathbb{E}_{t} f_{t+j}
$$

The transversality condition puts a constraint on the rate at which the exchange rate can grow.

The "no-bubbles" solutions indicates that the exchange rate is the present value of expected future values of the economic fundamentals. This is in view with the "asset" approach to the exchange rate according to which the exchange rate should be expected to behave just like other assets, such as stocks and bonds.

\subsection{Interactions between the Properties of the Fundamental Process and Those of the Exchange Rate Process}

We see that the exchange rate is a function of the fundamentals process. Therefore, the properties of the fundamentals have serious implications on the properties of the exchange rate process. Conversely, the observed characteristics of the exchange rate series put some restrictions on the potential characteristics of the fundamentals process. In this section we look at the implications of some well known stylized facts about exchange rate data for the characteristics of the fundamentals series.

For empirical purposes, we follow Mark characterization setting $\psi=1$ and use the expression

$$
f_{t}=m_{t}-m_{t}^{\star}-\left(y_{t}-y_{t}^{\star}\right)
$$

Two common stylized facts are as follows:

1) The deviation of the price from the fundamentals displays substantial persistence and much less volatility than the exchange rate returns.

2) The volatility of exchange rate returns, that is of $\Delta s_{t}$, is virtually indistinguishable from stock return volatility.

At this stage of the analysis, we want to focus on some empirical analysis by specifically looking at some descriptive statistics about the economic fundamentals, $f_{t}$, as defined in (0.18).

To address the excess volatility in the exchange rate returns relative to changes in the fundamentals, as in Mark [4], the growth rate of the economic fundamentals is assumed to follow the following $\operatorname{AR}(1)$ stationary process

$$
\Delta f_{t}=\rho \Delta f_{t-1}+\epsilon_{t}
$$

where $\epsilon_{t}$ is assumed iid with mean 0 and variance $\sigma_{\epsilon}^{2}$. No normality assumption is necessary.

The k-step ahead prediction formula is

$$
\mathbb{E}_{t}\left(\Delta f_{t+j}\right)=\rho^{j} \Delta f_{t}
$$


Alternatively, we obtain

$$
\begin{aligned}
\mathbb{E}_{t}\left(f_{t+j}\right) & =f_{t}+\sum_{k=1}^{j} \rho^{j} \Delta f_{t} \\
& =f_{t}+\frac{1-\rho^{j}}{1-\rho} \rho \Delta f_{t} \\
& =f_{t}+\frac{1}{1-\rho} \rho \Delta f_{t}-\frac{\rho^{j}}{1-\rho} \rho \Delta f_{t}
\end{aligned}
$$

We then obtain

$$
\begin{aligned}
s_{t} & =\gamma \sum_{j=0}^{\infty} \psi^{j}\left(f_{t}+\frac{1}{1-\rho} \rho \Delta f_{t}-\frac{\rho^{j}}{1-\rho} \rho \Delta f_{t}\right) \\
& =\gamma \sum_{j=0}^{\infty} \psi^{j} f_{t}+\gamma \sum_{j=0}^{\infty} \frac{\psi^{j}}{1-\rho} \rho \Delta f_{t}-\gamma \sum_{j=0}^{\infty} \frac{(\psi \rho)^{j}}{1-\rho} \rho \Delta f_{t} \\
& =\frac{\gamma}{1-\psi} f_{t}+\frac{\gamma \rho}{(1-\psi)(1-\rho)} \Delta f_{t}-\frac{\gamma \rho}{(1-\rho \psi)(1-\rho)} \Delta f_{t}
\end{aligned}
$$

Thus, the exchange rate solution can be simplified and we have the following formula

$$
\begin{aligned}
s_{t} & =f_{t}+\frac{\rho \gamma}{1-\rho}\left(\frac{1}{1-\psi}-\frac{1}{1-\rho \psi}\right) \Delta f_{t} \\
& =f_{t}+\frac{\rho \gamma}{1-\rho}\left(\frac{\psi(1-\rho)}{(1-\psi)(1-\rho \psi)}\right) \Delta f_{t} \\
& =f_{t}+\left(\frac{\gamma}{1-\psi}\right) \psi\left(\frac{\rho}{1-\rho \psi}\right) \Delta f_{t}
\end{aligned}
$$

Thus, we obtain the exchange rate solution to the standard FPMM

$$
s_{t}=f_{t}+\left(\frac{\rho \psi}{1-\rho \psi}\right) \Delta f_{t}
$$

At this point, we want to compare the variance of the exchange rate returns, $\Delta s_{t}$ with the variance of the change in fundamentals, $\Delta f_{t}$. We have

$$
\begin{aligned}
\operatorname{Var}\left(\Delta s_{t}\right) & =\operatorname{Var}\left(f_{t}+\left(\frac{\rho \psi}{1-\rho \psi}\right) \Delta f_{t}-f_{t-1}-\left(\frac{\rho \psi}{1-\rho \psi}\right) \Delta f_{t-1}\right) \\
& =\operatorname{Var}\left(\frac{1}{1-\rho \psi} \Delta f_{t}-\frac{\rho \psi}{1-\rho \psi} \Delta f_{t-1}\right) \\
& =\mathbb{V a r}\left(a_{1} \Delta f_{t}+a_{2} \Delta f_{t-1}\right) \\
& =a_{1}^{2} \mathbb{V} a r\left(\Delta f_{t}\right)+a_{2}^{2} \operatorname{Var}\left(\Delta f_{t-1}\right)+2 a_{1} a_{2} \operatorname{Cov}\left(\Delta f_{t}, \Delta f_{t-1}\right)
\end{aligned}
$$

Since the series $\left\{\Delta f_{t}\right\}$ is assumed to be stationary, then we have $\operatorname{Var}\left(\Delta f_{t}\right)=\operatorname{Var}\left(\Delta f_{t-1}\right)$ and $\operatorname{Cov}\left(\Delta f_{t}, \Delta f_{t-1}\right)=\rho \operatorname{Var}\left(\Delta f_{t}\right)$. Therefore, we obtain

$$
\begin{aligned}
\operatorname{Var}\left(\Delta \mathrm{s}_{t}\right) & =\frac{1}{(1-\rho \psi)^{2}}\left(\operatorname{Var}\left(\Delta f_{t}\right)+\rho^{2} \psi^{2} \operatorname{Var}\left(\Delta f_{t}\right)-2 \rho^{2} \psi \operatorname{Var}\left(\Delta f_{t}\right)\right) \\
& =\left(\frac{1+\rho^{2} \psi^{2}-2 \rho^{2} \psi}{(1-\rho \psi)^{2}}\right) \operatorname{Var}\left(\Delta f_{t}\right) \\
& =\left(\frac{(1-\rho \psi)^{2}+2 \rho \psi(1-\rho)}{(1-\rho \psi)^{2}}\right) \operatorname{Var}\left(\Delta f_{t}\right)
\end{aligned}
$$


Hence, we see clearly that

$$
\operatorname{Var}\left(\Delta s_{t}\right)>\operatorname{Var}(\Delta f)_{t}
$$

Figure 1 shows that the series in level $\left\{f_{t}\right\}$ are not stationary. If they have unit root the $\mathrm{AR}(1)$ process specified above for the economic fundamentals does not explain the empirical fact that exchange rate returns are more volatile than the growth rate of the fundamentals.

\section{Some Characteristics of the Empirical Distribution of the Fundamentals}

Given the implications of the properties of the fundamentals for the characteristics of the exchange rate process, it is important to analyze some essential aspects of the empirical distribution of the fundamentals, $\left\{f_{t}\right\}$.

\subsection{Some Sample Statistics}

First, we present a set of sample statistics in Table 1 . The series $\left\{f_{t}\right\}$ is computed using quarterly data on money supplies on both the domestic and foreign countireis from $1973 Q_{3}-2016 Q_{1}$ for Japan and Canada, from $1998 Q_{2}-2016 Q_{1}$ for Sweden, and from $1987 Q_{1}-2016 Q_{1}$ for the United Kingdom. Quarterly GDP is usually unavailable for most countries. Therefore, an Industrial production index is usually used as a proxy for national income. The data are available on the website of the OECD. One important goal is to assess the similarity of the distribution of the series $\left\{f_{t}\right\}$ to the normal dis-

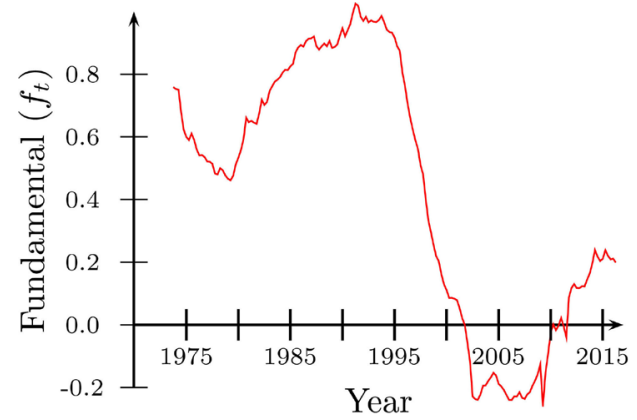

(a) Japan

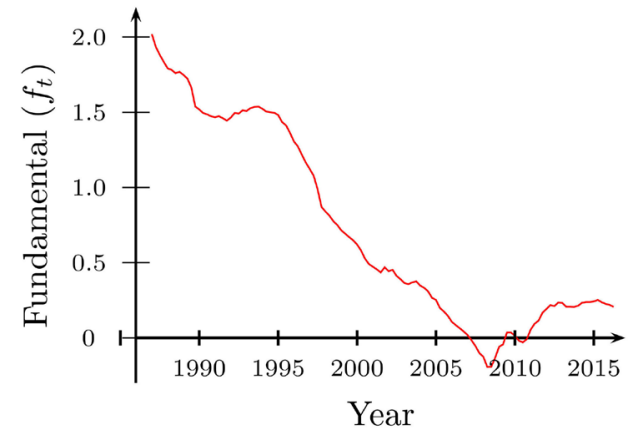

(c) UK

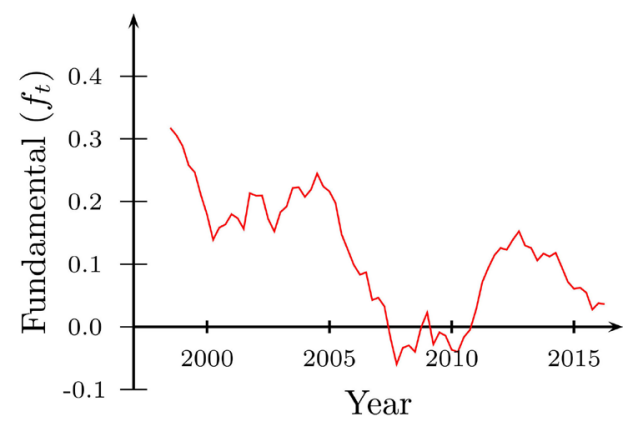

(b) Sweden

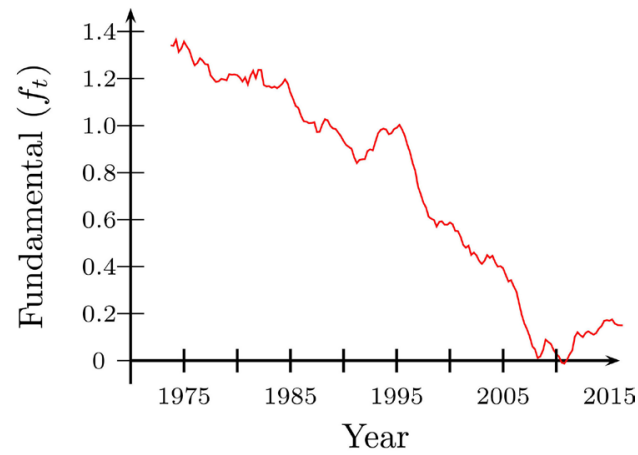

(d) Canada

Figure 1. Plots of the economic fundamentals series. 
Table 1. Descriptive statistics on the economic fundamentals $\left(\left\{f_{t}\right\}\right)$ for Japan, Sweden, UK, and Canada.

\begin{tabular}{ccccc}
\hline & Japan & Sweden & UK & Canada \\
\hline Minimum & -0.2609 & -0.0596 & -0.1933 & -0.0126 \\
Maximum & 1.0248 & 0.3175 & 2.0194 & 1.3654 \\
Mean & 0.4276 & 0.1142 & 0.7214 & 0.7288 \\
Median & 0.5140 & 0.1206 & 0.4540 & 0.8861 \\
Std.Dev & 0.4196 & 0.0946 & 0.6519 & 0.4397 \\
C.V. & 0.9813 & 0.8283 & 0.9037 & 0.6034 \\
Skewness & -0.2323 & -0.0026 & 0.4138 & -0.2935 \\
Ex. kurtosis & -1.3819 & -0.8627 & -1.3613 & -1.3769 \\
nobs & 171 & 72 & 118 & 171 \\
\hline
\end{tabular}

tribution. As a result, we will first look into the sample or empirical coefficient of kurtosis commonly defined as

$$
\kappa=\frac{1}{T} \frac{\sum_{t=1}^{T}\left(Y_{t}-\bar{Y}\right)^{4}}{\left[\frac{1}{T} \sum_{t=1}^{T}\left(Y_{t}-\bar{Y}\right)^{2}\right]^{2}} .
$$

It is clear that the distribution of the $\left\{f_{t}\right\}$ series is not normal as indicated at least by the excess kurtosis. Since the skewness is negative for Sweden and Japan, the data skewed to the left, that the left tail is longer. But, given that the skewness is between -0.5 and 0.5 , the distribution can be viewed as approximately symmetric. Figure 2 shows the density of the economic fundamentals estimated using a normal kernel.

A quick observation confirms our analysis, particularly for Japan and Sweden.

From this analysis, we observe that the series $\left\{f_{t}\right\}$ does not appear to have a normal distribution.

Let $S(f)$ be the coefficient of skewness and $\kappa(f)$ be the coefficient of kurtosis. We can also test the hypotheses:

1) $H_{0}: S(f)=0 ; H_{a}: S(f) \neq 0$

2) $H_{0}: \kappa(f)-3=0 ; H_{a}: \kappa(f)-3 \neq 0$

The $\mathrm{t}$-statistics for the above tests as well as the corresponding $\mathrm{p}$-value are presented in Table 2. Additionally, the Jarque and Bera [5] statistics, which can be viewed as a combination of the above statistics is also presented.

According to the table at a $5 \%$ significance level we cannot reject the hypothesis that the distributions of the series are symmetric, but we can reject the hypothesis of zero excess kurtosis as well as the hypothesis of normality.

This analysis may seem unnecessary. However, it actually has very important implications in terms of exchange rate modeling in both the discrete and continuous time as well as aset pricing modeling. The following section tackles the issue of stationarity.

\subsection{Stationarity of the Fundamentals}

Given any time series, one important question that is often to be considered is whether 


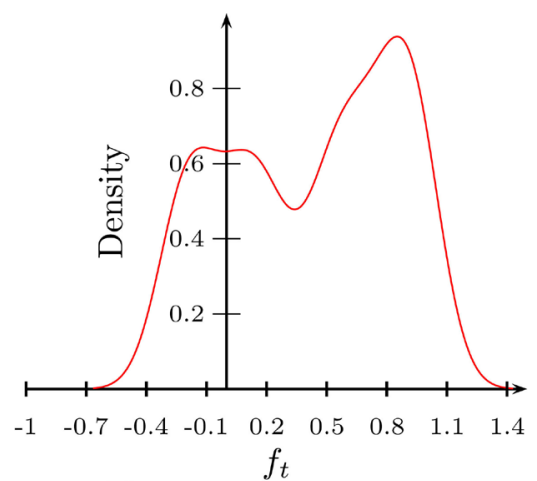

1.0

(a) Japan

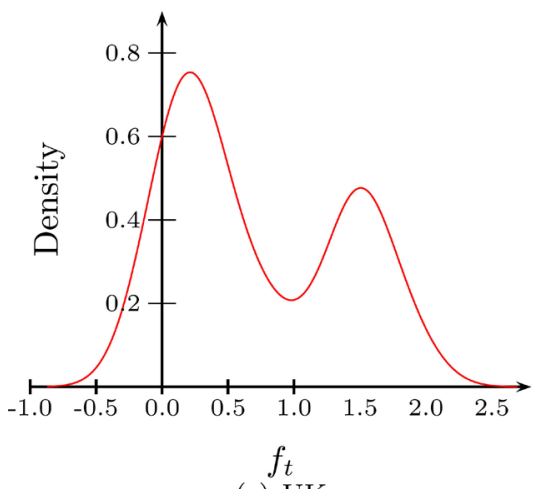

(c) UK

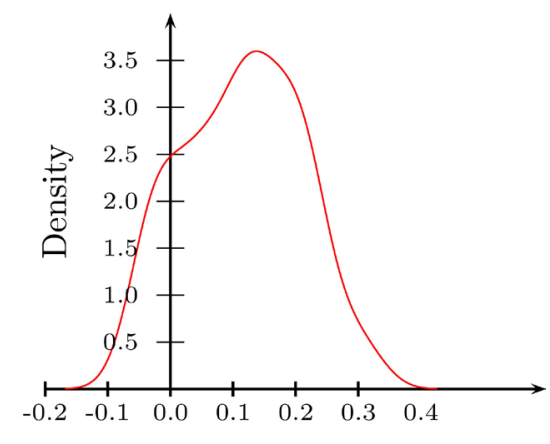

$f_{t}$

(b) Sweden

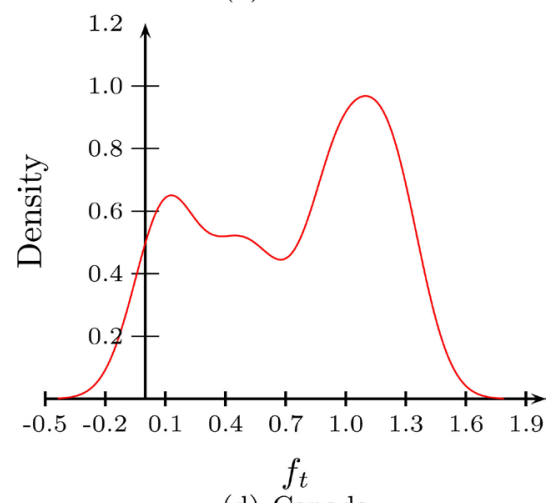

(d) Canada

Figure 2. Density estimation.

Table 2. Test of normality.

\begin{tabular}{ccccccccc}
\hline & skew & $t_{\text {skew }}$ & p-value & kurt & $t_{\text {kurt }}$ & p-value & JB & p-value \\
\hline Japan & -0.2323 & -1.2403 & 0.2149 & 1.6181 & 4.3191 & 0.0000 & 20.1927 \\
Sweden & -0.0026 & -0.0089 & 0.9929 & 2.1373 & 3.7019 & 0.0002 & 13.7039 & 0.0000 \\
UK & 0.4138 & 1.8349 & 0.0665 & 1.6387 & 3.6336 & 0.0003 & 16.5696 & 0.0003 \\
Canada & -0.2935 & -1.5669 & 0.1171 & 1.6231 & 4.3325 & 0.0000 & 21.2260 & 0.0000 \\
\hline
\end{tabular}

the series is stationary or non stationary. The examination of stationarity is important because doing regression analysis with non stationary time series can lead to spurious regression results. We now tackle this question for each of the $\left\{f_{t}\right\}$ series considered above, namely for respectively US-JAPAN series, US-SWEDEN, US-CANADA, and US-UK data on output and money supplies from 1973: $Q_{1}$ to $1997: Q_{4}$ (Figure 3 \& Figure 4).

We conduct the analysis using the Augmented Dickey-Fuller test statistic or alternatively the KPSS test procedure. The first step is to identify the optimal order of the autoregressive process that fits the quarterly change in the fundamentals. To do so we start by plotting the sample autocorrelation function and the sample partial autocorrelation function for each series $\left(f_{-} t\right)$. For Japan we see that the first, the second, and the ninth partial autocorrelation coefficients appear to be significant at a $5 \%$ significance level suggesting an $\mathrm{AR}(2)$ or $\mathrm{AR}(9)$ model. Since the model that minimizes the Akaike 
Information criterion is an $\mathrm{AR}(9)$ and since the autocorrelation coefficients are significant for several lags, the autoregressive model of order 9 appears to be a good model for this series. A similar analysis for Sweden, the United Kingdom, and Canada suggest that we work with autoregressive processes of order 1, 2, and 3 respectively.

The Augmented Dickey Fuller test that follows is based on the above autoregressive models. The test's null hypothesis assumes that the series is non stationary while the alternative hypothesis states that the series is stationary. Since the distribution of the ADF test statistic under the null hypothesis is not the usual t-distribution, Monte Carlo methods are used approximate the distribution of the statistic. The null hypothesis of nonstationarity is rejected as long as the test statistic is smaller than a commonly specified critical value or the associated p-value is less than a chosen significance level. Otherwise, stationarity should be maintained. In Table 3 the p-value are computed using Monte Carlo methods and model-based bootstrap. The latter is chosen to account for

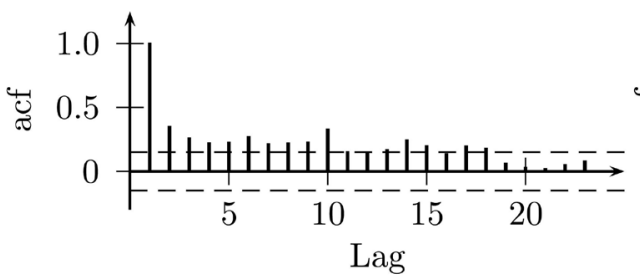

(a) Japan

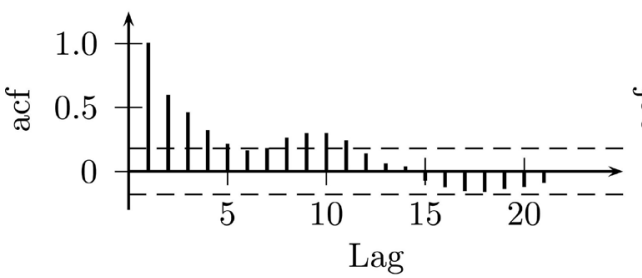

(c) UK

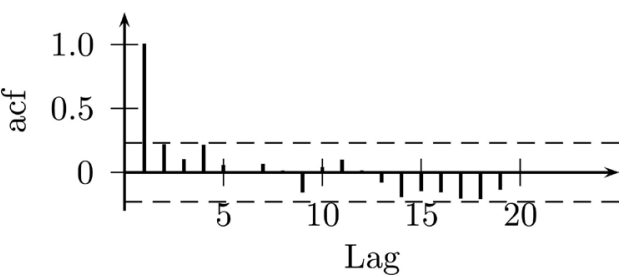

(b) Sweden

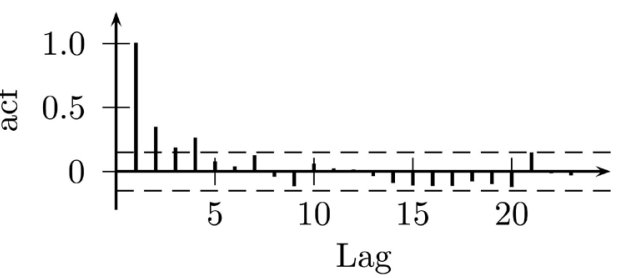

(d) Canada

Figure 3. Sample autocorrelation function of the quaterly change in the fundamentals for Japan, Sweden, the United Kingdom, and Canada.

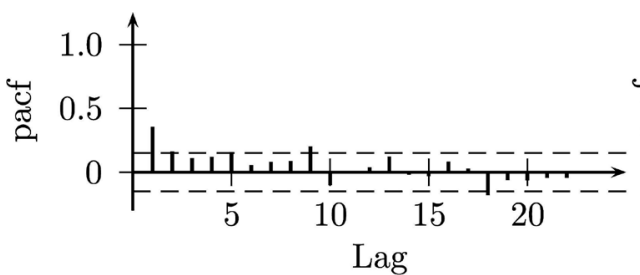

(a) Japan

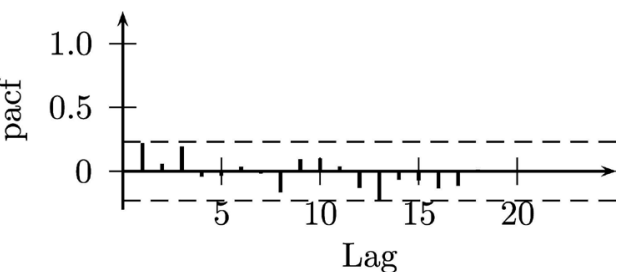

(b) Sweden

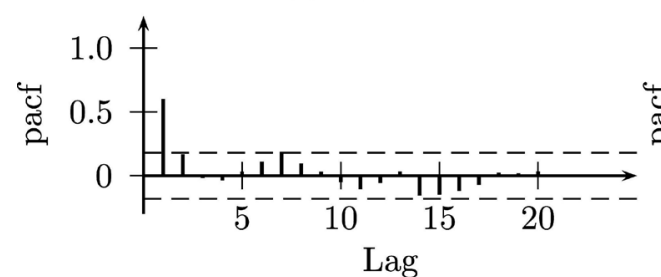

(c) UK

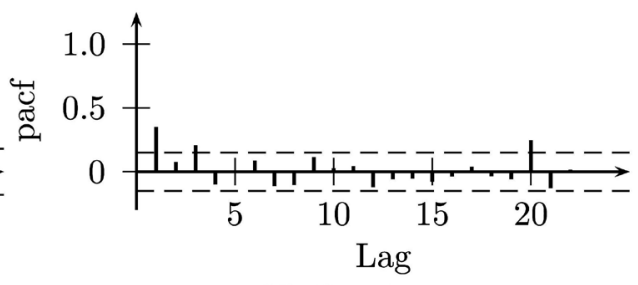

(d) Canada

Figure 4. Sample partial autocorrelation function of the quarterly change in the fundamentals for Japan, Sweden, UK, and Canada. 
Table 3. Augmented dickey fuller test.

\begin{tabular}{ccccc}
\hline & Japan & Sweden & UK & Canada \\
\hline statistics & -2.8841 & -1.9489 & -0.7624 & -2.5585 \\
Asympt. p-value & 0.2071 & 0.5961 & 0.9625 & 0.3431 \\
Bootstrap p-value & 0.2229 & 0.6153 & 0.9527 & 0.3066 \\
Lag order & 9.0000 & 1.0000 & 2.0000 & 3.0000 \\
\hline
\end{tabular}

Table 4. KPSS test.

\begin{tabular}{ccccc}
\hline & Japan & Sweden & UK & CANADA \\
\hline statistics & 2.6537 & 1.8265 & 3.6722 & 4.2132 \\
p-value & 0.0100 & 0.0100 & 0.0100 & 0.0100 \\
Lag order & 3.0000 & 1.0000 & 2.0000 & 3.0000 \\
\hline
\end{tabular}

the low power of ADF test reported in the literature.

The KPSS test procedure is more commonly used in empirical work. The null hypothesis is that the series is stationary. Here, for completeness, we report both testing procedures.

Table 3 shows that for all the series the Asymptotic and the Bootstrap p-values are greater than $20 \%$. We cannot reject the null hypothesis that the series are non-stationary. This observation is confirmed in Table 4 where the p-values of the KPSS test are all less than or equal to $1 \%$, which provides evidence against stationarity.

To complete the analysis, we explore whether the series exhibit Autoregressive Conditional Heteroskedasticity (ARCH) or Generalized ARCH (GARCH) effects. Stock prices usually exhibit ARCH and GARCH properties. Moreover, given that most international economists believe that exchange rates behave like stock prices, we would expect exchange rates to have such properties. We will examine ARCH and GARCH effects in the next section.

\subsection{ARCH and GARCH Effects for the Fundamentals}

We examine the conditional variance of the above four series to determine the presence of ARCH and GARCH effects. We start by estimating the conditional means of the series by determining the ARMA model that minimizes the Akaike Information criterion. We then generate the residuals which are used to compute the sample autocorrelation function and the sample partial autocorrelation functions of the squared residuals. They are plotted in the following figures (Figure 5 \& Figure 6).

According to the sample autocorrelation functions of the square of the residuals, Japan and the UK cannot be modeled as a pure Moving Average process. However, a Moving Average process of order 0 seems to be appropriate for Sweden, and in the case of Canada one may be able to use a Moving Average process of order 3.

Further, looking at the sample partial autocorrelation functions, one can see that the first, and the ninth lags are significant for Japan, which suggests a possible AR(1) mo- 


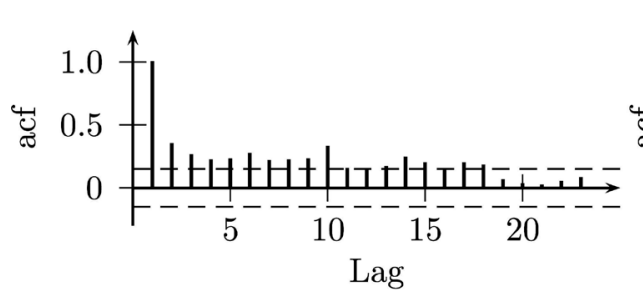

(a) Japan

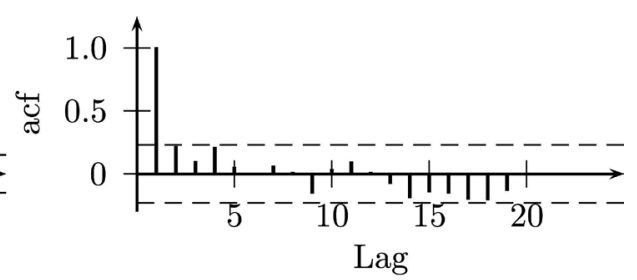

(b) Sweden

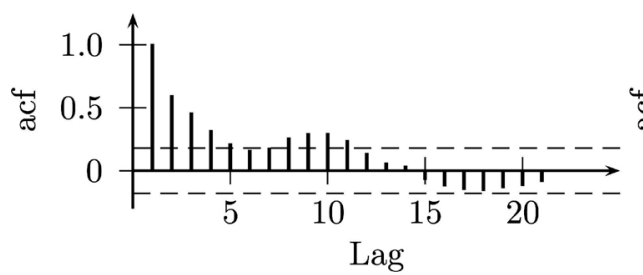

(c) UK

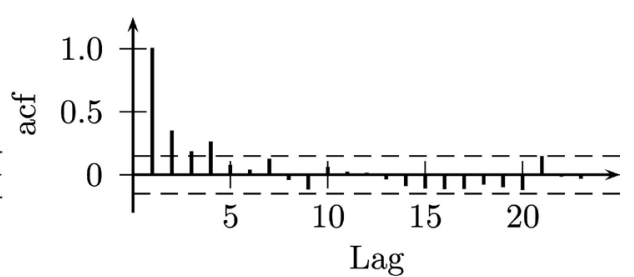

(d) Canada

Figure 5. Sample autocorrelation function of the square of the residuals obtained from the autoregressive model that minimizes the Akaike Information criterion (AIC).

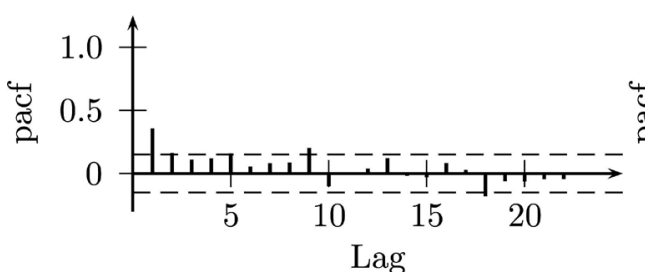

(a) Japan

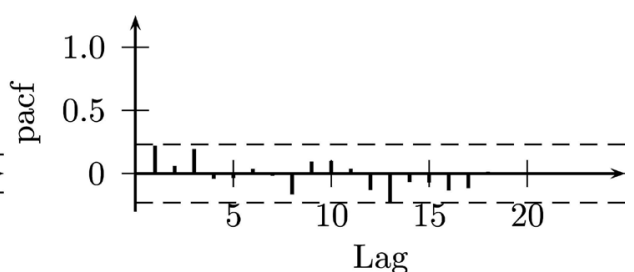

(b) Sweden

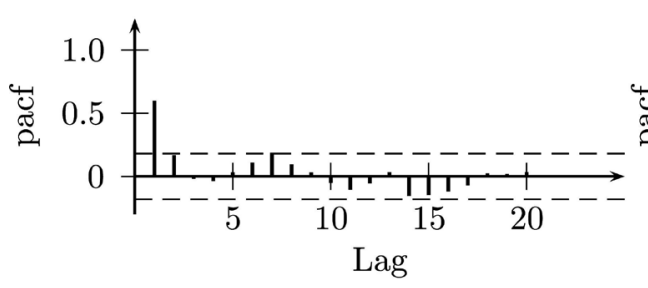

(c) UK

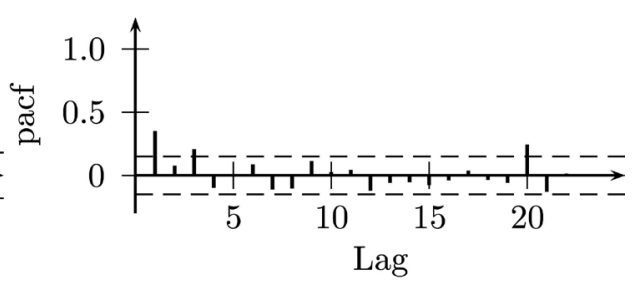

(d) Canada

Figure 6. Sample partial correlation function of the square of the residuals obtained from the autoregressive model that minimizes the Akaike Information criterion (AIC).

del; for the UK an AR(1) model may be appropriate; the series for Sweden seem to be white noise, while for Canada the partial autocorrelation function seems to point toward an $\mathrm{AR}(3)$. The above observation suggests an $\mathrm{ARCH}(1)$ for Japan, an $\mathrm{ARCH}(1)$ for the UK, a GARCH $(3,3)$ for Canada, and no ARCH effect for Sweden.

We also use the Akaike information criterion (AIC) to identify the best autoregressive models for the square of the residuals. The models obtained are $\mathrm{ARCH}(1)$ for Japan and the UK and $\mathrm{ARCH}(0)$ for Sweden and Canada.

To test for ARCH effects or the presence of ARCH effects, the most commonly used test is the Lagrange multiplier(LM) test proposed by Engle. The test is usually performed by first estimating the best fitting regression equation usually called the "mean equation", which can be an appropriate ARMA or AR model and then use the residuals to estimate the coefficients. For example, to test for an $\mathrm{ARCH}(2)$ model for Japan, we collect the squared residuals from the autoregressive model with the smallest AIC 
$(\mathrm{AR}(9))$ and then run the regression

$$
\hat{e}_{t}^{2}=\gamma_{0}+\gamma_{1} \hat{e}_{t-1}^{2}+\gamma_{2} \hat{e}_{t-2}^{2}+v_{t}
$$

Of course, $v_{t}$ is an error term. The null hypothesis is $H_{0}: \gamma_{1}=0, \gamma_{2}=0$ versus $H_{1}$ :at least one coefficient is not 0 . The null hypothesis states that there are no $\mathrm{ARCH}$ effects. More generally, for the general case, the null hypothesis states that all the coefficients should be zero and the alternative hypothesis states that at least one coefficient should be zero. The LM statistic is $L M=(T-q) R^{2}$, where $\mathrm{T}$ is the sample size an q is the number of lags $\hat{e}_{t}^{2}$ (here $q=1$ ) and $R^{2}$ is the coefficient of determination. Under the null hypothesis, the LM statistic has a chi-square distribution with $\mathrm{q}$ degrees of freedom in large samples. Hence, the null hypothesis is rejected if $(T-q) R^{2}>\chi_{1-\alpha, q}^{2}$ or the associated p-value is less than the chosen significance level, and conclude that $\mathrm{ARCH}$ effects are present in the data. The test was implemented and the results are provided in Table 5.

As the table indicated there is evidence in favor of conditional heteroskedasticity for Japan and the UK, but we cannot reject the hypothesis that residuals for Sweden and Canada are white noise.

The estimates of the corresponding ARCH models for Japan and the UK are presented in Table 6.

Table 5. LM test for ARCH effect.

\begin{tabular}{cccc}
\hline & LM statistic & p value & ARCH order $(\mathrm{q})$ \\
\hline Japan & 26.90 & 0.00 & 2.00 \\
Sweden & 0.97 & 0.33 & 1.00 \\
UK & 22.25 & 0.00 & 2.00 \\
Canada & 1.82 & 0.18 & 1.00 \\
\hline
\end{tabular}

Table 6. Estimates of the parameters AR-ARCH models for Japan and the UK.

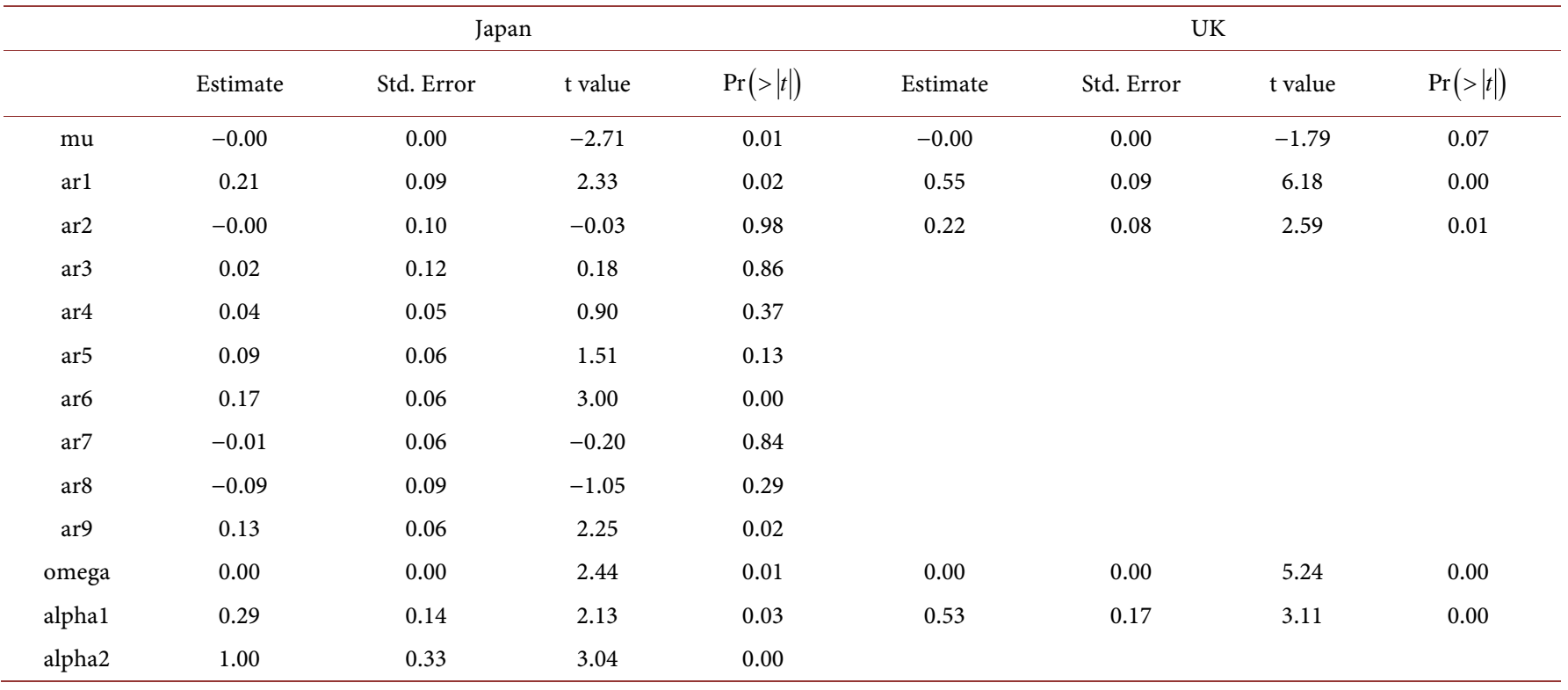




\section{Conclusion}

In this paper, we have analyzed some empirical aspects of the economic fundamentals that is shown to be the driving force of exchange rate behavior. The analysis shows that this fundamental series does not appear to be normally distributed as indicated by the excess kurtosis and skewness as well as the estimated kernel density as indicated by the data for several countries. Also, we observe that some ARCH effects are present for most data while GARCH effects are not that common. This has important implications for modeling exchange rate and also the analysis of target zone models.

\section{References}

[1] Dornbusch, R. (1976) Expectations and Exchange Rate Dynamics. Journal of Political Economy, 84, 1161-1176. https://doi.org/10.1086/260506

[2] Frenkel, J.A. (1976) A Monetary Approach to the Exchange Rate: Doctrinal Aspects and Empirical Evidence. Scandinavian Journal of Economics, 78, 200-224. https://doi.org/10.2307/3439924

[3] Mussa, M. (1976) The Exchange Rate, the Balance of Payments, and Monetary and Fiscal Policy under a Regime of Controlled Floating. Scandinavian Journal of Economics, 78, 229248. https://doi.org/10.2307/3439926

[4] Mark, N.C. (2001) International Macroeconomics and Finance: Theory and Econometric Methods. Wiley-Blackwell.

[5] Jarque, C.M. and Bera, A.K. (1987) A Test for Normality of Observations and Regression Residuals. International Statistical Review, 55, 163-172. https://doi.org/10.2307/1403192

Submit or recommend next manuscript to SCIRP and we will provide best service for you:

Accepting pre-submission inquiries through Email, Facebook, LinkedIn, Twitter, etc.

A wide selection of journals (inclusive of 9 subjects, more than 200 journals)

Providing 24-hour high-quality service

User-friendly online submission system

Fair and swift peer-review system

Efficient typesetting and proofreading procedure

Display of the result of downloads and visits, as well as the number of cited articles

Maximum dissemination of your research work

Submit your manuscript at: http://papersubmission.scirp.org/

Or contact me@scirp.org 